\title{
Return to play in long-standing adductor-related groin pain: a Delphi study among experts looking for criteria.
}

Luca Vergani

U.S. Saints Pagnano

Marco Cuniberti ( $\sim$ Marco.Cuniberti@aspetar.com )

Aspetar Orthopaedic and Sports Medicine Hospital https://orcid.org/0000-0002-4865-7808

Massimo Zanovello

A.P.D. Robur et Fides Varese

Daniele Maffei

Bergamo Basket 2014

Abdulaziz Farooq

Aspetar Orthopaedic and Sports Medicine Hospital

Cristiano Eirale

Paris St Germain

\section{Original Research Article}

Keywords: Long-standing groin pain, Sports injuries, Return to play, Delphi

Posted Date: April 28th, 2021

DOl: https://doi.org/10.21203/rs.3.rs-440785/v1

License: (c) (1) This work is licensed under a Creative Commons Attribution 4.0 International License.

Read Full License 


\section{Abstract}

Background: Groin pain is a high incidence and prevalence injury in multidirectional field sports such as soccer, ice hockey, rugby and Australian football codes. Long-standing adductor-related groin pain is a persistent clinical condition and a frequent complaint in athletes involved in sports that require multiplanar movement patterns (change of direction, high-speed sprinting and kicking). To date, the lack of rehabilitation guidelines and return-to-play criteria makes this clinical entity difficult to manage.

The aim of the present Delphi was to define, based on expert opinion and practical experience, the criteria used in clinical practice to establish a safe return-to-play in multidirectional sports in athletes suffering from long-standing adductor-related groin pain.

Methods: 40 experts were invited to fill a 3-Round Delphi questionnaire. In round 1, open-ended and closed questions about 9 different sections (palpation, flexibility, strength, patient-reported outcome measures, imaging, intersegmental control, performance tests, sport-specific skills, training load) were proposed to investigate return to play evaluation criteria used by each expert. Responses were analysed and coded to produce round 2 questionnaire that investigated only the sections and the items that reached the cut-off value ( $\geq 70 \%$ ). Round 3 questionnaire was based on sections and items that reached cut-off value in previous rounds and experts rated their agreement for return to play criteria with a 5-point Likert Scale. Descriptive statistics enabled interpretation of consensus.

Results: High participation rate (80\%) and response rate across the 3 rounds (100\%) were recorded. 6 sections reached positive consensus in round 1,1 section reached negative consensus.

In round 2 positive consensus was confirmed only for 3 sections and negative consensus for 1 section. In round 3, positive agreement was established for strength (3 items), performance tests ( 3 items) and sportspecific skills ( 2 items) sections. Negative consensus was confirmed for imaging section.

Conclusion: Despite most of items did not reach cut-off values, a solid positive consensus between experts was reached for strength, performance tests and sport-specific skills sections and a solid negative consensus was obtained for imaging section. These findings could be a useful practical tool for clinicians in the return-to-play continuum.

\section{Background}

Groin pain provides a massive challenge for all those involved in diagnostic, rehabilitation and physical preparation of athletes at all levels due to the complex anatomy of the groin region and the poor understanding of the adverse mechanisms that predispose the athlete to injury. $(1,2)$

Studies in professional sports have found groin injury to be the fourth most common injury in soccer(3) and the third most common injury in Australian rules football;(4) it has also shown to have a high prevalence in ice hockey(5) and rugby.(6) 
Long-standing adductor-related groin pain (LARGP) is a persistent clinical condition with gradual or sudden onset characterised by adductor tenderness and pain on resisted adduction testing.(7) It is a frequent complaint in athletes involved in multidirectional field sports that require multiplanar movement patterns, such as change of direction (COD), $(8,9)$ high-speed sprinting $(4,10)$ and kicking.(11)

In accordance with Strategic Assessment of Risk and Risk Tolerance (StARRT) framework, $(12,13)$ return to play (RTP) decision making is a complex process based on the evaluation of health and activity risks but it is also influenced by the assessment of the risk tolerance modifiers.

Combining information from biological, psychological and social standpoints can help all RTP decisionmakers (clinician, physiotherapist, coach) to make optimal and shared decisions.(14)

Nevertheless, RTP criteria for many common injuries like groin pain are not based on solid scientific evidence due to the lack of clarity and consensus on the term 'return to play'.(14) So far, no studies have specified which criteria should be assessed by clinicians to allow an athlete suffering from groin pain a timely and fully RTP.

The aim of this Delphi study was to define, based on expert opinion and practical experience, the criteria used in clinical practice to establish a safe RTP in multidirectional sports in athletes suffering from LARGP.

In particular, the present study aimed to reach a consensus between experts and researchers to provide biological/physical criteria that should be taken into consideration in the RTP decision-making process.

\section{Methods}

The Delphi is a group facilitation technique that seeks to obtain consensus on the opinion of "experts" through a series of structured questionnaires commonly referred to as "rounds".(15) The Delphi is therefore an interactive multistage process designed to combine opinion into group consensus. $(16,17)$ The initial questionnaire may also collect qualitative comments which are feedback to the participants in a quantitative form through a second questionnaire.(15)

This scientific method has been effectively used in Sports Medicine research.(18-21)

The whole process lasted from February 2020 to July 2020. A total of 3 rounds were carried out using the platform https://www.google.com/intl/it/forms/about/

\section{Steering Committee}

The Delphi survey was created by a 4-member steering committee consisting of four sports physiotherapists supervised by a sport physician with a strong background in clinical research and elite sport.

\section{Expert Panel}


In accordance to previously Delphi studies published,(21-23) to be considered elegible, to participate in the study, only healthcare practitioners meeting the following inclusion criteria were deemed elegible: 1) 2 or more peer-reviewed publications in the field of groin pain in athletes and 2) experience in scientific methodology and/or 3) clinical expert and designated member of the conference organising committee and 4) evidence-based attitude; and 5) sufficient knowledge of English language.

According to "snowballing method",(24) each expert contacted could, in turn, invite 3 additional experts then submitted to inclusion criteria.

The experts were contacted $(n=40)$ via e-mail and they were asked to be willing to participate in the study and information about the aim and methodology of the study were provided. Participants were given 1 month to complete the questionnaire in each round, with email reminders sent to non-responders after 10 days and 20 days, respectively.

\section{Round 1}

Round 1 was the only round prepared before the beginning of the study because each subsequent round was dependent on the responses from the previous one.

Written explanation of the experimental procedure was provided to each individual; this included the aims of the study, the experimental procedures to be utilised and a clear explanation of the use of the definition of LARGP(7) and the use of the definition of RTP.(25) Individuals then provided written, informed consent before participating in the study.

The first round was divided into 2 parts. The first one investigated the "demographic" characteristics of the participants: profession, affiliation, years of experience in the field of sports medicine, the number of athletes treated with groin pain/year, the number of peer-reviewed studies published around groin pain (Table 1).

The second part included 38 questions divided into 9 different sections (palpation, flexibility, strength, patient-reported outcome measures (PROMs), imaging, intersegmental control, performance tests, sport specific skills, training load) with the objective of investigating the clinical assessment of each researcher in the evaluation of RTP.

During the first round both close-ended and open-ended questions were used.

The sentence "Do you use/analyse "X" when evaluating RTP in LARGP?" was the first closed-ended question put at the beginning of each section.

Within the section there were also open-ended questions to provide the researcher the possibility to motivate his answer and/or indicate aspects not considered in the question asked.

In accordance with Joyner et al.,(26) the answers to each open-ended question were divided into categories. In order to reduce categorisation bias responses were independently coded by 2 different 
researchers ( $M Z$ and $M C)$, and compared only at the end to discuss the final categorization.(20) The 3 categories with the highest consensus were then included in the second round and submitted to other researchers.(26)

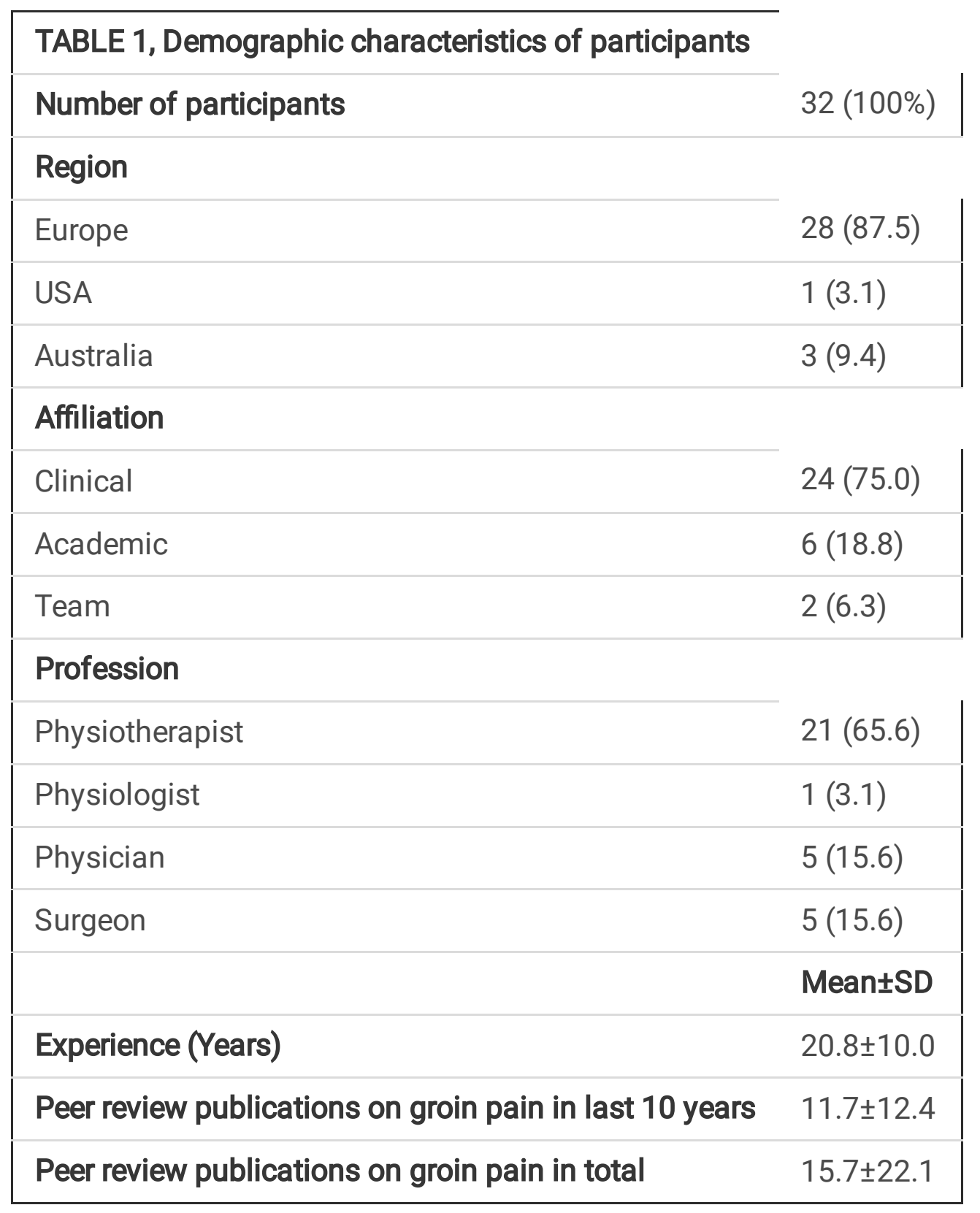

\section{Round 2}

At the beginning of the second round, the categories that reached the cut-off value were listed and the aim of the study was explained again.

Round 2 questionnaire investigated only the categories that reached the cut-off value. The first question in each section asked whether or not the researcher considered the category concerned as a RTP criterion.

The following questions were formulated based on the answer given within the round 1 questionnaire, feedbacks and suggestions in order to go into more details surrounding each of the categories. 


\section{Round 3}

Within round 3 only the answers that have reached the cut-off value in round 2 have been entered. For all items that reached the cut-off value in round 2, researchers were asked to express their degree of consensus by using the Likert-scale(27) with values from 1 to 5 (Strongly Disagree, Disagree, Neutral, Agree, Strongly Agree).

At the end, participants were given the opportunity to share comments on the whole Delphi process.

\section{Data analysis}

Data from all Delphi rounds were collected using Google online forms and extracted to IBM SPSS V.21 for statistical analysis. Two of the steering committee members independently performed content analyses and a third investigator was consulted whenever there were any disagreements/ambiguity around the tagging, categorising and interpreting the responses. In closed-ended questions (option yes/no or specific items from a list to be selected), the frequency of each expert's response was recorded and converted to a percentage (\%). For open-ended questions, following recommendations by Côté et al.,(28) qualitative data (ie, expert answers, justifications and suggestions) were coded, listed and compared in order to produce clusters of similar concepts which adequately represent the information received by experts. If responses to analogies reached $\geq 70 \%$ threshold $(18,20,23,29,30)$ that particular item/criterion was considered as reaching consensus among the experts and was thereafter retained and elaborated on in further rounds, while those concepts not reaching consensus were discarded. This approach was used throughout rounds 1 and 2. Regarding round 3, ratings for each item coded (1-5) were expressed as means with standard deviation (SD). Consensus between participants was measured using coefficient of variation (CV\%) and percentage agreement (\%AGR):(31) CV\% is a measure of dispersion and \%AGR was defined as the percentage of responses falling within the top two categories of the 5-point scale (Agree and Strongly agree).

Agreement between participants was also evaluated across all items using Kendall's W coefficient (W) of concordance, a non-parametrical statistic that is used to assess strength and changes of agreement between raters.(31) In round 3, Mean rating $\geq 3.5, \mathrm{CV} \% \leq 30 \%, \% \mathrm{AGR} \geq 70 \%$ and $\mathrm{W}<0.05$ were defined as concurrent requirements for consensus in order to define a final agreement between experts for RTP in LARGP. Statistical significance was set at $p<0.05$.

\section{Results}

32 experts over $40(80 \%)$ accepted the invitation to participate in the study and the response rate across the three rounds was $100 \%$.

On the 9 different criteria proposed for RTP, full consensus was achieved on strength, performance tests, sport-specific skills (positive agreement) and imaging (negative agreement).

\section{Round 1}


The sections that reached positive consensus in round 1 were: Palpation (78\%), Strength (97\%), PROMs (72\%), Intersegmental Control (72\%), Performance tests (78\%), Sport-specific skills (87,5\%).

The section Imaging reached a negative consensus (75\%), however the sections Flexibility and Training Load did not reach any consensus.

As reported in Table 2, consensus was achieved by 1 item (1/2) in the Palpation section, 5 items (5/21) in the Strength section, 2 items (2/8) in Intersegmental Control, 2 items (2/8) in Performance tests and 2 items $(2 / 2)$ in Sport-specific skills.

Furthermore, Table 2 contains the items list (Top3 approved by 2 researchers through independent coding, based on participants' answers and suggestions. The list was included in the round 2 questionnaire.

Items of sections that achieved negative or no consensus were not added to the round 2 .

However, all the items included in the round 1 are available on the attachment of supplementary material.

\section{Round 2}

In round 2, 4 out of the 7 sections reached consensus as RTP criteria while the other 3 sections did not reach it.

A positive consensus has been confirmed for the sections: Strength (94\%), Performance tests (91\%), Sport-specific skills (91\%).

A negative consensus has been confirmed for Imaging (78\%).

Palpation, PROMs and Intersegmental Control lost the consensus obtained in round 1.

In the section of Strength 1 item (1/29) reached consensus, in Performance tests 1 item (1/7) and in Sport-specific skills 3 items $(3 / 5)$.

Percentages were described in detail in Table 3.

A list of all items and full percentages is available within the supplementary material.

Therefore, a form with 4 sections and 11 items was finalised for round 3 (agreement round). 


\section{TABLE 3, Expert panel answers in}

round 2 .

\begin{tabular}{llll} 
Section & Item & Consensus & \multicolumn{1}{c}{$\begin{array}{l}\text { Percentage } \\
\text { (\%) }\end{array}$} \\
\hline Palpation & Use as a criterion in RTP & NC & 68.8 \\
\hline Strength & Use as a criterion in RTP & + & 93.8 \\
\hline $\begin{array}{l}\text { Tests to evaluate hip } \\
\text { adductors' isometric } \\
\text { strength }\end{array}$ & $\begin{array}{l}\text { No tests reached } \\
\text { cut-off value } \\
(\geq 70 \%)\end{array}$ & \\
\hline $\begin{array}{l}\text { Tests to evaluate hip adductors' } \\
\text { eccentric strength }\end{array}$ & $\begin{array}{l}\text { No tests reached cut-off } \\
\text { value }(\geq 70 \%)\end{array}$ & & \\
\hline $\begin{array}{l}\text { Analysis of strength in other } \\
\text { muscle groups }\end{array}$ & NC & 66.7 & \\
\hline
\end{tabular}

Other parameters considered (except pain)

Side-to-Side Symmetry

PROMs Use as a criterion in RTP NC

$\begin{array}{llll}\text { Imaging } & \text { Use as a criterion in RTP } & - & 78.1 \\ \text { Intersegmental Control } & \text { Use as a criterion in RTP } & \text { NC } & 34.3 \\ \text { Performance Tests } & \text { Use as a criterion in RTP } & + & 90.6 \\ & \begin{array}{l}\text { Others parameters } \\ \text { considered (except pain) }\end{array} & & \end{array}$

$\begin{array}{lll}\text { Athlete feedback } \quad+\quad 82.8 & +\end{array}$

Sport-Specific Skills $\quad$ Use as a criterion in RTP $\quad+\quad 90.6$

\begin{tabular}{|c|c|c|}
\hline & \multicolumn{2}{|c|}{$\begin{array}{l}\text { Others parameters } \\
\text { considered (except pain) }\end{array}$} \\
\hline Athlete feedback & + & 86.2 \\
\hline Performance in skills execution & + & 75.9 \\
\hline Quality of movement & + & 72.4 \\
\hline
\end{tabular}

(+) Positive consensus; (-) Negative consensus; NC,No consensus

\section{Round 3}


Kendall's W was significant at $0.03(p<0.001)$.

Round 3 final agreement is presented in Figure 1.

Agreement was established for the Strength section with 3 items, the Performance tests section with 3 items and the Sport-specific skills section with 2 items.

A negative consensus was established for the Imaging section.

\section{Discussion}

The aim of this Delphi study was to achieve an agreement between experts on RTP criteria in LARGP.

The main finding was that assessment of strength, performance tests and sport-specific skills would seem to be a sine qua non in RTP complex process in athletes affected by LARGP.

As reported in Figure 2, it was established that during strength evaluation it would seem crucial to analyse adductors isometric and eccentric strength considering "side-to-side symmetry".

Planned/unplanned COD analysis seems to be considered as a criterion when performance tests are evaluated; athletes should be confident during completion and totally pain free.

At the same time, during sport-specific skills analysis, athletes should be confident and completely pain free during execution.

Although few items and 4 out of 9 categories reached final agreement, low CV\% (mean 18.3\%, range 12.9 - 28.7), high \%AGR (mean $84.4 \%$, range $65.6 \%$ - 96.9\%) and $W=0.03(p<0.001)$ show the robustness of the consensus established.

\section{Strength}

Experts agreed on the importance of strength assessment as a RTP criterion (96.9\%). Specifically, at the end of 3 rounds, consensus was achieved for the evaluation of hip adductors isometric strength $(75 \%)$ and eccentric strength (84.4\%).

These findings are in line with several studies(32-34) and are supported by evidence that highlights the usefulness of strength both as outcome measure $(35,36)$ and rehabilitation criterion in groin pain. $(34,37,38)$

Despite no agreement established for strength tests to be used, the squeeze test $0^{\circ}$ for isometric strength (66.7\% of answers) and eccentric strength assessment in side-lying position (53.3\%) would seem to be assessment methods with a wider consensus between experts.

Side-to-side symmetry is a discriminating factor in RTP: $87.6 \%$ of participants consider this parameter as a criterion to analyse during RTP process. 
Although several studies support strength assessments of other hip muscle groups, $(39,40)$ in our study none of these groups achieved expert consensus.

No final agreement was established for strength analysis of other muscle groups; nevertheless trunk flexors got a high rate of positive response in round $2(90 \%)$. A total of 18 out of the 20 participants consider strength of aforementioned muscle complex important to evaluate. This could be an interesting clinical tip to consider even though no final consensus was achieved.

\section{Imaging}

Imaging is the only section that achieved negative consensus (93.7\%). In fact, experts strongly agree to not consider or include imaging methods among RTP criteria.

Although imaging can be a valid diagnostic tool to support the clinical examination and identify red flags, (41) to date no study supports its use in RTP decision. Therefore, our finding would seem in agreement with literature.(42,43)

\section{Performance Tests}

Experts agree that analysis of performance tests can be considered as a criterion to establish RTP readiness in athletes suffering from LARGP $(93.7 \%)$.

No specific test reached the 3 rounds agreement, but a strong consensus (96.9\%) was achieved on the use of planned/unplanned COD to varying degrees (45-90-110-180').

Data established seems to strongly agree with the current evidence; $(8,44,45)$ in fact COD is considered an evocative and provocative movement in groin pain $(46,47)$ and both a sport-specific movement and a reliable outcome measure. $(48,49)$

Experts agree that athletes must be fully asymptomatic (78.1\%) and confident (93.7\%) during COD execution. This seems to be confirmed by Serner et al.(50) that used COD, absence of symptoms and athlete confidence among RTP criteria, even if their study was on acute adductor injuries.

\section{Sport-specific skills}

To date, no study in the literature thoroughly examined the use of sport-specific skills in RTP in LARGP.

However, skills such as "kicking a ball" are considered potential causes of groin pain onset.(51)

Buckthorpe et al.(52) recommended the analysis of sport-specific movements to allow the athletes a full and safe RTS.

In the present study, the sport-specific skills section achieved solid consensus (96.9\%). In addition, experts agree that athletes must be asymptomatic (75\%) and self-confident $(96.9 \%)$ during the execution of sportspecific tasks. 
Even if parameters such as quality of movement and performance in skills execution did not reach agreement, the percentage obtained among participants $(65.6 \%)$ suggests that these aspects could play a role as well.

\section{No agreement sections}

Three categories that did not achieve consensus (palpation, PROMs and intersegmental control) would seem to be in some way relevant in RTP decision-making although they are not considered as criteria.

It was established $78.1 \%$ of experts use palpation in RTP stage but just $68.8 \%$ of them uses it as criterion. Despite literature seeming to agree in assuming that pain-free palpation is important during RTP when considering other muscle injuries,(18,53) no expert consensus was achieved for LARGP. In round 1, 56.5\% of respondents (13/23) allows pain in palpation, while $43.5 \%(10 / 23)$ requires a complete absence of symptoms.

A total of $71.9 \%$ of experts uses PROMs but only $59.4 \%$ of them uses it as criteria in RTP. The PROMs most used by clinicians and researchers $(91.3 \%-21 / 23)$ is HAGOS.(54)

Intersegmental Control analysis seems to be useful in managing groin pain.(8) Even if for this category no agreement was established, intersegmental control is used by $71.9 \%$ of sample. In particular, $78.3 \%$ of respondents $(18 / 23)$ use single leg squat as a test to assess motor control.

Analysis of flexibility did not reach the consensus in its utilisation. Nevertheless, evidence highlights the importance of getting total hip range of motion to avoid recurrence episodes of groin pain.(55)

Even if training load (TL) cannot be considered a valid tool to assess injury risk,(56) as reported by Cummins et al.,(57) load management could represent a helpful tool to manage RTP progression. However, in the present Delphi study neither internal nor external load parameters reached consensus.

\section{Conclusion}

Our research showed a solid consensus among experts on 4 out of 9 sections.

As suggested by our expert panel, RTP framework is a complex process composed of several decisionmodifiers, however these findings could be a useful practical tool (Fig. 2) for clinicians in the "first-step" planning of RTP physical aspects assessment.

Nevertheless, it would be desirable to establish a more solid and broad experts' consensus, including assessment of other items, psychosocial factors and a wider expert's cohort.

\section{Declarations}

Ethics Approval and consent to participate: Not applicable. 
Consent for publication: Informed consent was obtained from all experts.

Availability of data and materials: The datasets used and analysed during the current study are available from the corresponding author on reasonable request. Data include round 1, round 2 and round 3 Delphi questions and further demographic data.

Competing interest: Luca Vergani, Marco Cuniberti, Massimo Zanovello, Daniele Maffei, Abdulaziz Farooq and Cristiano Eirale declare that they have no competing interests.

Funding: No funding was received related to this article.

Authors' contribution: LV devised the study.

LV, MC and CE developed the concept and design of study protocol.

All authors approved the study protocol.

LV and MC were responsable for initial contact with expert panel. LV and DM created the online surveys.

$\mathrm{MC}, \mathrm{MZ}$ and $\mathrm{AF}$ collected data.

MC MZ performed analysis and interpretation data with AF acting as a 3rd reviewer.

AF performed statistycal analysis LV, CE, MZ and DM prepared full draft of manuscript.

All authors approved the final version of the manuscript prior to submission.

Acknowledgements: The authors thank all the experts who took the time to participate in this Delphi study. Without their feedback, suggestions and contribution it would not have been possible doing this project.

The authors also specially thank Pullinger Samuel, Bassis Giulia and Tamagno Ricardo for their assistance in language and figures editing which have improved the manuscript.

\section{Abbreviations}

LARGP: Longstanding Adductor-Related Groin Pain

RTP: Return To Play

HAGOS: Hip And Groin Outcome Score

TL: Training Load

IC: Intersegmental Control 
PROMs: Patient-Reported Outcome Measures

COD: Change Of Direction

StARRT: Strategic Assessment of Risk and Risk Tolerance

\section{References}

1. Falvey EC, Franklyn-Miller A, McCrory PR. The groin triangle: a patho-anatomical approach to the diagnosis of chronic groin pain in athletes. Br J Sports Med. 2009 Mar;43(3):213-20.

2. Joyce D, Lewindon D. Sports Injury Prevention and Rehabilitation: Integrating Medicine and Science for Performance Solutions [Internet]. 1st ed. Routledge; 2015. Available from: https://www.taylorfrancis.com/books/9780203066485

3. Ekstrand J, Krutsch W, Spreco A, van Zoest W, Roberts C, Meyer T, et al. Time before return to play for the most common injuries in professional football: a 16-year follow-up of the UEFA Elite Club Injury Study. Br J Sports Med. 2020 Apr;54(7):421-6.

4. Orchard J, Seward H. Epidemiology of injuries in the Australian Football League, seasons 1997-2000. Br J Sports Med. 2002 Feb;36(1):39-44.

5. Emery CA, Meeuwisse WH, Powell JW. Groin and abdominal strain injuries in the National Hockey League. Clin J Sport Med. 1999 Jul;9(3):151-6.

6. Brooks JHM, Fuller CW, Kemp SPT, Reddin DB. Epidemiology of injuries in English professional rugby union: part 2 training Injuries. Br J Sports Med. 2005 Oct;39(10):767-75.

7. Weir A, Brukner P, Delahunt E, Ekstrand J, Griffin D, Khan KM, et al. Doha agreement meeting on terminology and definitions in groin pain in athletes. Br J Sports Med. 2015 Jun;49(12):768-74.

8. King E, Franklyn-Miller A, Richter C, O'Reilly E, Doolan M, Moran K, et al. Clinical and biomechanical outcomes of rehabilitation targeting intersegmental control in athletic groin pain: prospective cohort of 205 patients. Br J Sports Med. 2018 Aug;52(16):1054-62.

9. Daniels KAJ, King E, Richter C, Falvey É, Franklyn-Miller A. Changes in the kinetics and kinematics of a reactive cut maneuver after successful athletic groin pain rehabilitation. Scand J Med Sci Sports. 2020 Oct 23;

10. O'Connor D. Groin injuries in professional rugby league players: a prospective study. J Sports Sci. 2004 Jul;22(7):629-36.

11. Bradshaw CJ, Bundy M, Falvey E. The diagnosis of longstanding groin pain: a prospective clinical cohort study. Br J Sports Med. 2008 Oct;42(10):851-4.

12. Shrier I. Strategic Assessment of Risk and Risk Tolerance (StARRT) framework for return-to-play decision-making. Br J Sports Med. 2015 Oct;49(20):1311-5.

13. Creighton DW, Shrier I, Shultz R, Meeuwisse WH, Matheson GO. Return-to-play in sport: a decisionbased model. Clin J Sport Med. 2010 Sep;20(5):379-85. 
14. Ardern CL, Glasgow P, Schneiders A, Witvrouw E, Clarsen B, Cools A, et al. 2016 Consensus statement on return to sport from the First World Congress in Sports Physical Therapy, Bern. Br J Sports Med. 2016 Jul;50(14):853-64.

15. Hasson F, Keeney S, McKenna H. Research guidelines for the Delphi survey technique. Journal of Advanced Nursing. 2000;32(4):1008-15.

16. Lynn MR, Layman EL, Englebardt SP. Nursing administration research priorities. A national Delphi study. J Nurs Adm. 1998 May;28(5):7-11.

17. McKenna HP. The Delphi technique: a worthwhile research approach for nursing? J Adv Nurs. 1994 Jun;19(6):1221-5.

18. van der Horst N, Backx F, Goedhart EA, Huisstede BM, HIPS-Delphi Group. Return to play after hamstring injuries in football (soccer): a worldwide Delphi procedure regarding definition, medical criteria and decision-making. Br J Sports Med. 2017 Nov;51(22):1583-91.

19. McCall A, Pruna R, Van der Horst N, Dupont G, Buchheit M, Coutts AJ, et al. Exercise-Based Strategies to Prevent Muscle Injury in Male Elite Footballers: An Expert-Led Delphi Survey of 21 Practitioners Belonging to 18 Teams from the Big-5 European Leagues. Sports Med. 2020 Sep;50(9):1667-81.

20. Zambaldi M, Beasley I, Rushton A. Return to play criteria after hamstring muscle injury in professional football: a Delphi consensus study. Br J Sports Med. 2017 Aug 1;51(16):1221-6.

21. Weir A, Hölmich P, Schache AG, Delahunt E, Vos R-J de. Terminology and definitions on groin pain in athletes: building agreement using a short Delphi method. Br J Sports Med. 2015 Jun 1;49(12):8257.

22. Donaldson A, Cook J, Gabbe B, Lloyd DG, Young W, Finch CF. Bridging the gap between content and context: establishing expert consensus on the content of an exercise training program to prevent lower-limb injuries. Clin J Sport Med. 2015 May;25(3):221-9.

23. Kleynen M, Braun SM, Bleijlevens MH, Lexis MA, Rasquin SM, Halfens J, et al. Using a Delphi technique to seek consensus regarding definitions, descriptions and classification of terms related to implicit and explicit forms of motor learning. PLoS One. 2014;9(6):e100227.

24. Sheu S-J, Wei I-L, Chen C-H, Yu S, Tang F-I. Using snowball sampling method with nurses to understand medication administration errors. J Clin Nurs. 2009 Feb;18(4):559-69.

25. Bisciotti GN, Volpi P, Alberti G, Aprato A, Artina M, Auci A, et al. Italian consensus statement (2020) on return to play after lower limb muscle injury in football (soccer). BMJ Open Sport Exerc Med. 2019;5(1):e000505.

26. Joyner (Melito) HS, Smith D. Using Delphi Surveying Techniques to Gather Input from NonAcademics for Development of a Modern Dairy Manufacturing Curriculum. Journal of Food Science Education. 2015;14(3):88-115.

27. van Alphen A, Halfens R, Hasman A, Imbos T. Likert or Rasch? Nothing is more applicable than good theory. J Adv Nurs. 1994 Jul;20(1):196-201.

28. Côté J, Salmela JH, Baria A, Russell SJ. Organizing and Interpreting Unstructured Qualitative Data. The Sport Psychologist. 1993 Jun 1;7(2):127-37. 
29. Verhagen AP, de Vet HC, de Bie RA, Kessels AG, Boers M, Bouter LM, et al. The Delphi list: a criteria list for quality assessment of randomized clinical trials for conducting systematic reviews developed by Delphi consensus. J Clin Epidemiol. 1998 Dec;51(12):1235-41.

30. Huisstede BMA, Hoogvliet P, Coert JH, Fridén J, European HANDGUIDE Group. Multidisciplinary consensus guideline for managing trigger finger: results from the European HANDGUIDE Study. Phys Ther. 2014 Oct;94(10):1421-33.

31. von der Gracht HA. Consensus measurement in Delphi studies: Review and implications for future quality assurance. Technological Forecasting and Social Change. 2012 Oct 1;79(8):1525-36.

32. Kloskowska P, Morrissey D, Small C, Malliaras P, Barton C. Movement Patterns and Muscular Function Before and After Onset of Sports-Related Groin Pain: A Systematic Review with Metaanalysis. Sports Med. 2016 Dec;46(12):1847-67.

33. Mosler AB, Weir A, Serner A, Agricola R, Eirale C, Farooq A, et al. Musculoskeletal Screening Tests and Bony Hip Morphology Cannot Identify Male Professional Soccer Players at Risk of Groin Injuries: A 2Year Prospective Cohort Study. Am J Sports Med. 2018 May;46(6):1294-305.

34. Serner A, Weir A, Tol JL, Thorborg K, Lanzinger S, Otten R, et al. Return to Sport After Criteria-Based Rehabilitation of Acute Adductor Injuries in Male Athletes: A Prospective Cohort Study. Orthop J Sports Med. 2020 Jan;8(1):2325967119897247.

35. Nevin F, Delahunt E. Adductor squeeze test values and hip joint range of motion in Gaelic football athletes with longstanding groin pain. J Sci Med Sport. 2014 Mar;17(2):155-9.

36. Thorborg K, Branci S, Nielsen MP, Tang L, Nielsen MB, Hölmich P. Eccentric and Isometric Hip Adduction Strength in Male Soccer Players With and Without Adductor-Related Groin Pain: An Assessor-Blinded Comparison. Orthop J Sports Med. 2014 Feb;2(2):2325967114521778.

37. Ishøi L, Thorborg K. Copenhagen adduction exercise can increase eccentric strength and mitigate the risk of groin problems: but how much is enough! Br J Sports Med. 2021 Feb 24;

38. Harøy J, Clarsen B, Wiger EG, Øyen MG, Serner A, Thorborg K, et al. The Adductor Strengthening Programme prevents groin problems among male football players: a cluster-randomised controlled trial. Br J Sports Med. 2019 Feb;53(3):150-7.

39. Mosler AB, Agricola R, Weir A, Hölmich P, Crossley KM. Which factors differentiate athletes with hip/groin pain from those without? A systematic review with meta-analysis. Br J Sports Med. 2015 Jun;49(12):810.

40. Gore SJ, Franklyn-Miller A, Richter C, Falvey EC, King E, Moran K. Is stiffness related to athletic groin pain? Scand J Med Sci Sports. 2018 Jun;28(6):1681-90.

41. Thorborg K, Reiman MP, Weir A, Kemp JL, Serner A, Mosler AB, et al. Clinical Examination, Diagnostic Imaging, and Testing of Athletes With Groin Pain: An Evidence-Based Approach to Effective Management. J Orthop Sports Phys Ther. 2018 Apr;48(4):239-49.

42. Serner A, Weir A, Tol JL, Thorborg K, Yamashiro E, Guermazi A, et al. Associations Between Initial Clinical Examination and Imaging Findings and Return-to-Sport in Male Athletes With Acute Adductor Injuries: A Prospective Cohort Study. Am J Sports Med. 2020 Apr;48(5):1151-9. 
43. Branci S, Thorborg K, Nielsen MB, Hölmich P. Radiological findings in symphyseal and adductorrelated groin pain in athletes: a critical review of the literature. Br J Sports Med. 2013 Jul;47(10):6119.

44. Franklyn-Miller A, Richter C, King E, Gore S, Moran K, Strike S, et al. Athletic groin pain (part 2): a prospective cohort study on the biomechanical evaluation of change of direction identifies three clusters of movement patterns. Br J Sports Med. 2017 Mar;51(5):460-8.

45. Marshall BM, Franklyn-Miller AD, Moran KA, King EA, Strike SC, Falvey ÉC. Can a Single-Leg Squat Provide Insight Into Movement Control and Loading During Dynamic Sporting Actions in Patients With Athletic Groin Pain? J Sport Rehabil. 2016 May;25(2):117-25.

46. Gabbe BJ, Finch CF, Wajswelner H, Bennell KL. Predictors of lower extremity injuries at the community level of Australian football. Clin J Sport Med. 2004 Mar;14(2):56-63.

47. Chaudhari AMW, Jamison ST, McNally MP, Pan X, Schmitt LC. Hip adductor activations during run-tocut manoeuvres in compression shorts: implications for return to sport after groin injury. J Sports Sci. 2014;32(14):1333-40.

48. Welch N, Richter C, Moran K, Franklyn-Miller A. Rehabilitation interventions need more than methodological standardisation: an individualised approach. BMJ Open Sport Exerc Med. 2020;6(1):e000899.

49. Rivadulla AR, Gore S, Preatoni E, Richter C. Athletic groin pain patients and healthy athletes demonstrate consistency in their movement strategy selection when performing multiple repetitions of a change of direction test. J Sci Med Sport. 2020 May;23(5):442-7.

50. Serner A, Hölmich P, Tol JL, Thorborg K, Lanzinger S, Otten R, et al. Progression of Strength, Flexibility, and Palpation Pain During Rehabilitation of Athletes With Acute Adductor Injuries: A Prospective Cohort Study. J Orthop Sports Phys Ther. 2021 Mar;51(3):126-34.

51. Kerbel YE, Smith CM, Prodromo JP, Nzeogu MI, Mulcahey MK. Epidemiology of Hip and Groin Injuries in Collegiate Athletes in the United States. Orthop J Sports Med. 2018 May;6(5):2325967118771676.

52. Buckthorpe M, Della Villa F, Della Villa S, Roi GS. On-field Rehabilitation Part 2: A 5-Stage Program for the Soccer Player Focused on Linear Movements, Multidirectional Movements, Soccer-Specific Skills, Soccer-Specific Movements, and Modified Practice. J Orthop Sports Phys Ther. 2019 Aug;49(8):5705.

53. De Vos R-J, Reurink G, Goudswaard G-J, Moen MH, Weir A, Tol JL. Clinical findings just after return to play predict hamstring re-injury, but baseline MRI findings do not. Br J Sports Med. 2014 Sep;48(18):1377-84.

54. Thorborg K, Hölmich P, Christensen R, Petersen J, Roos EM. The Copenhagen Hip and Groin Outcome Score (HAGOS): development and validation according to the COSMIN checklist. Br J Sports Med. 2011 May;45(6):478-91.

55. Nevin F, Delahunt E. Adductor squeeze test values and hip joint range of motion in Gaelic football athletes with longstanding groin pain. J Sci Med Sport. 2014 Mar;17(2):155-9. 
56. Impellizzeri FM, Woodcock S, Coutts AJ, Fanchini M, McCall A, Vigotsky AD. What Role Do Chronic Workloads Play in the Acute to Chronic Workload Ratio? Time to Dismiss ACWR and Its Underlying Theory. Sports Med. 2021 Mar;51(3):581-92.

57. Cummins $\mathrm{C}$, Orr R, O'Connor H, West C. Global positioning systems (GPS) and microtechnology sensors in team sports: a systematic review. Sports Med. 2013 Oct;43(10):1025-42.

\section{Table 2}

\section{Figures}


TABLE 2, Expert panel answers in round 1

\begin{tabular}{|c|c|c|c|}
\hline \multirow{2}{*}{$\begin{array}{l}\text { Section } \\
\text { Palpation }\end{array}$} & \multirow{2}{*}{$\begin{array}{l}\text { Item } \\
\text { Use of palpation in RTP process }\end{array}$} & \multicolumn{2}{|c|}{ Consensus Percentage (\%) } \\
\hline & & + & 78.1 \\
\hline & Presence of pain in palpation & + & 92.0 \\
\hline & Allow RTP with pain in palpation & $\mathrm{NC}$ & 56.5 \\
\hline & \multicolumn{3}{|l|}{ Other parameters considered ${ }^{a}$} \\
\hline & Pain parameters & \multicolumn{2}{|c|}{7 respondents $^{\mathrm{b}}$} \\
\hline & Localization & \multicolumn{2}{|c|}{5 respondents ${ }^{b}$} \\
\hline & Tightness & \multicolumn{2}{|c|}{4 respondents ${ }^{b}$} \\
\hline & Type of tissue & \multicolumn{2}{|c|}{4 respondents ${ }^{b}$} \\
\hline Flexibility & Flexibility analysis in RTP process & $\mathrm{NC}$ & 62.5 \\
\hline \multirow{20}{*}{ Strength } & Strength analysis in RTP process & + & 96.9 \\
\hline & $\begin{array}{l}\text { Hip muscle groups (type of } \\
\text { strength) }\end{array}$ & & \\
\hline & Adductors (Ecc/Iso/Con) & $\begin{array}{l}+ \text { Ecc ; + } \\
\text { Iso }\end{array}$ & $87.1 / 74.2 / 38.7$ \\
\hline & Abductors (Ecc/Iso/Con) & NC & $\begin{array}{l}51.6 / 51.6 / \\
12.9\end{array}$ \\
\hline & Extensors (Ecc/Iso/Con) & $\mathrm{NC}$ & $38.7 / 9.7 / 16.1$ \\
\hline & Flexors (Ecc/Iso/Con) & $\mathrm{NC}$ & $54.8 / 32.3 / 29.0$ \\
\hline & $\begin{array}{l}\text { Internal Rotators } \\
\text { (Ecc/Iso/Con) }\end{array}$ & NC & $38.7 / 9.7 / 22.6$ \\
\hline & $\begin{array}{l}\text { External Rotators } \\
\text { (Ecc/Iso/Con) }\end{array}$ & NC & $38.7 / 6.5 / 19.4$ \\
\hline & $\begin{array}{l}\text { Strength assessment of other muscle } \\
\text { groups }\end{array}$ & + & 71.0 \\
\hline & Which other areas? ${ }^{a}$ & & \\
\hline & Trunk group & \multicolumn{2}{|c|}{18 respondents $^{b}$} \\
\hline & Knee group & \multicolumn{2}{|c|}{9 respondents ${ }^{\mathrm{b}}$} \\
\hline & Calf complex group & \multicolumn{2}{|c|}{7 respondents $^{b}$} \\
\hline & Presence of pain in strength tests & + & 96.8 \\
\hline & Allow RTP with pain in strength tests & - & 70.0 \\
\hline & \multicolumn{3}{|l|}{ Other parameters considered ${ }^{a}$} \\
\hline & $\begin{array}{l}\text { Pain parameters } \\
\text { (location, grading) }\end{array}$ & \multicolumn{2}{|c|}{10 respondents $^{b}$} \\
\hline & Side-to-side comparison & \multicolumn{2}{|c|}{8 respondents ${ }^{b}$} \\
\hline & Ratios & \multicolumn{2}{|c|}{8 respondents ${ }^{b}$} \\
\hline & Baseline data & \multicolumn{2}{|c|}{7 respondents ${ }^{b}$} \\
\hline \multirow[t]{5}{*}{ PROMs } & Use of PROMs in RTP process & + & 71.9 \\
\hline & Which PROMs? ${ }^{a}$ & & \\
\hline & $\begin{array}{l}\text { Hip And Groin Outcome Score } \\
\text { (HAGOS) }\end{array}$ & \multicolumn{2}{|c|}{21 respondents $^{b}$} \\
\hline & Visual Analog Scale (VAS) & \multicolumn{2}{|c|}{2 respondents $^{b}$} \\
\hline & Internal PROMs & \multicolumn{2}{|c|}{2 respondents $^{\mathrm{b}}$} \\
\hline Imaging & Use of imaging in RTP process & - & 75.0 \\
\hline $\begin{array}{l}\text { Intersegmental } \\
\text { Control (IC) }\end{array}$ & IC tasks analysis in RTP process & + & 71.9 \\
\hline
\end{tabular}


Which IC tasks? ${ }^{\text {a }}$

Single leg squat

18 respondents $^{b}$

Squat

15 respondents $^{\mathrm{b}}$

Lunge

Presence of pain in IC tasks

13 respondents $^{b}$

Allow RTP with pain in IC tasks

82.6

Other parameters considered ${ }^{\mathrm{a}}$

Quality of movement

Side-to-side symmetry

Pain parameters

(location, grading)

Performance Tests

Performance tests analysis in RTP process

Which performance tests? ${ }^{a}$

Planned/Unplanned CoD (45-90-180)

T-test

Illinois test

Presence of pain in performance tests

Allow RTP with pain in performance tests

Other parameters considered ${ }^{\mathrm{a}}$ Performance/intensity

Grading of pain Movement control

10 respondents $^{b}$

3 respondents ${ }^{\mathrm{b}}$

2 respondents $^{\mathrm{b}}$

84.2

78.1

18 respondents $^{b}$

17 respondents $^{\mathrm{b}}$

13 respondents $^{\mathrm{b}}$

100

80.0

$+$

$-$

(

\begin{tabular}{|c|c|c|}
\hline & Performance/intensity & 8 respondents $^{b}$ \\
\hline & Grading of pain & 6 respondents $^{b}$ \\
\hline & Movement control & 4 respondents $^{\mathrm{b}}$ \\
\hline \multirow[t]{9}{*}{ Sport-Specific Skills } & $\begin{array}{l}\text { Sport-specific skills analysis in RTP } \\
\text { process }\end{array}$ & 87.5 \\
\hline & $\begin{array}{l}\text { Presence of pain in Sport-Specific } \\
\text { skills }\end{array}$ & 89.3 \\
\hline & $\begin{array}{l}\text { Allow RTP with pain in sport-specific } \\
\text { skills }\end{array}$ & 84.0 \\
\hline & Other parameters considered ${ }^{a}$ & \\
\hline & $\begin{array}{l}\text { Pain parameters } \\
\text { (location, grading) }\end{array}$ & 7 respondents $^{\mathrm{b}}$ \\
\hline & Performance/intensity & 5 respondents $^{b}$ \\
\hline & Specific tests & 3 respondents $^{b}$ \\
\hline & Quality of movement & 3 respondents $^{b}$ \\
\hline & Athlete feedback & 3 respondents $^{b}$ \\
\hline
\end{tabular}

\section{Training Load}

\begin{tabular}{lll}
$\begin{array}{l}\text { Internal Load monitoring in RTP } \\
\text { process }\end{array}$ & $\mathrm{NC}$ & 56.3 \\
\hline $\begin{array}{l}\text { External Load monitoring in RTP } \\
\text { process }\end{array}$ & $\mathrm{NC}$ & 59.4 \\
\hline
\end{tabular}

(+) Positive consensus; (-) Negative consensus; NC, No consensus;

a, Open-ended question; ${ }^{\mathrm{b}}$, Top 3 ranked preferences for open-ended question coded independently by 2 researchers;

Abbreviations: Ecc,Eccentric; Iso,Isometric; Conc,Concentric; PROMs, Patient Reported Outcome Measures; CoD, Changes of Direction 
Strength evaluation

Aralysis of isometric strength of hip adductor

Analysis of eccentric strength of hip adductor

Pain-free athletes in strength test:

Aralysis of side-to-side symmetry in strength tests

\section{IMAGING}

Imaging methods not as criterion for RTP

ixa

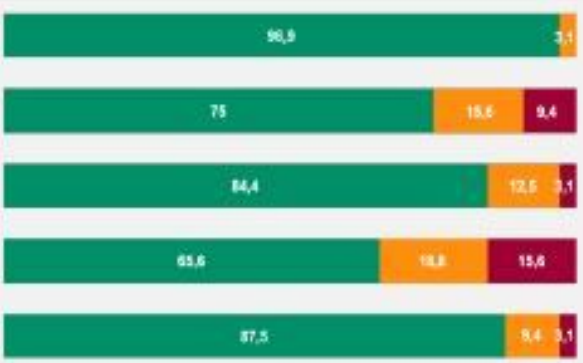

$\underset{\substack{\text { Rinal Agrous } \\ \text { (P) }}}{ }$

Agreement

$4.6 \pm 0.6$

Agreement

$2.9=09$

$\begin{array}{lll}\text { Agreement } & 4.240 .8 & 18.6\end{array}$

No Agreenvent $\quad 3.8 \pm 1.0 \quad 27.5$

Agreement $\quad 4.2 \pm 0.7 \quad 17.4$
ManesD Prosi

Agreement

\section{PERFORMANCE TESTS}

Performance tests evaluation

Uses planned/unplanned COD

Pain free in performance tests execution

Feedback during execution

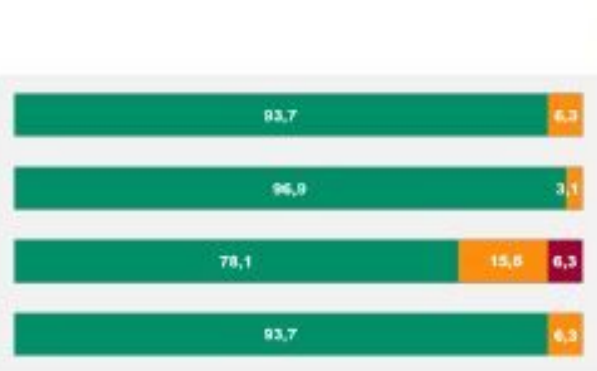

Final Apo

Agreement

Agreement

Agreement

Agreemeat

\section{SPORT-SPECIFIC SKILLS}

Sport-specific skills evaluation

Pain free in skill execution

Feedback during execution

Performance analysis durine execution

Aralysis of quality of movement on execution

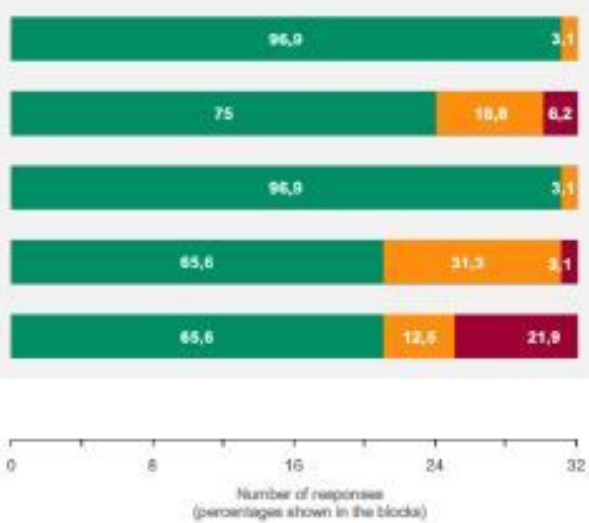

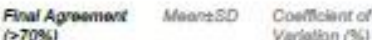

$\begin{array}{lll}\text { Agreement } & 4.6 \pm 0.5 & 12.2\end{array}$

$\begin{array}{lll}\text { Agreement } \quad 4.0 \pm 09 & 21.7\end{array}$

Agreement $\quad 4.5 \pm 0.6=127$

No Agreensent $\quad 3.8 \pm 0.7 \quad 19.2$

No Agreensent $\quad 3.5 \pm 1.0 \quad 28.7$

\section{Figure 1}

Round 3 final expert agreement on RTP criteria. 


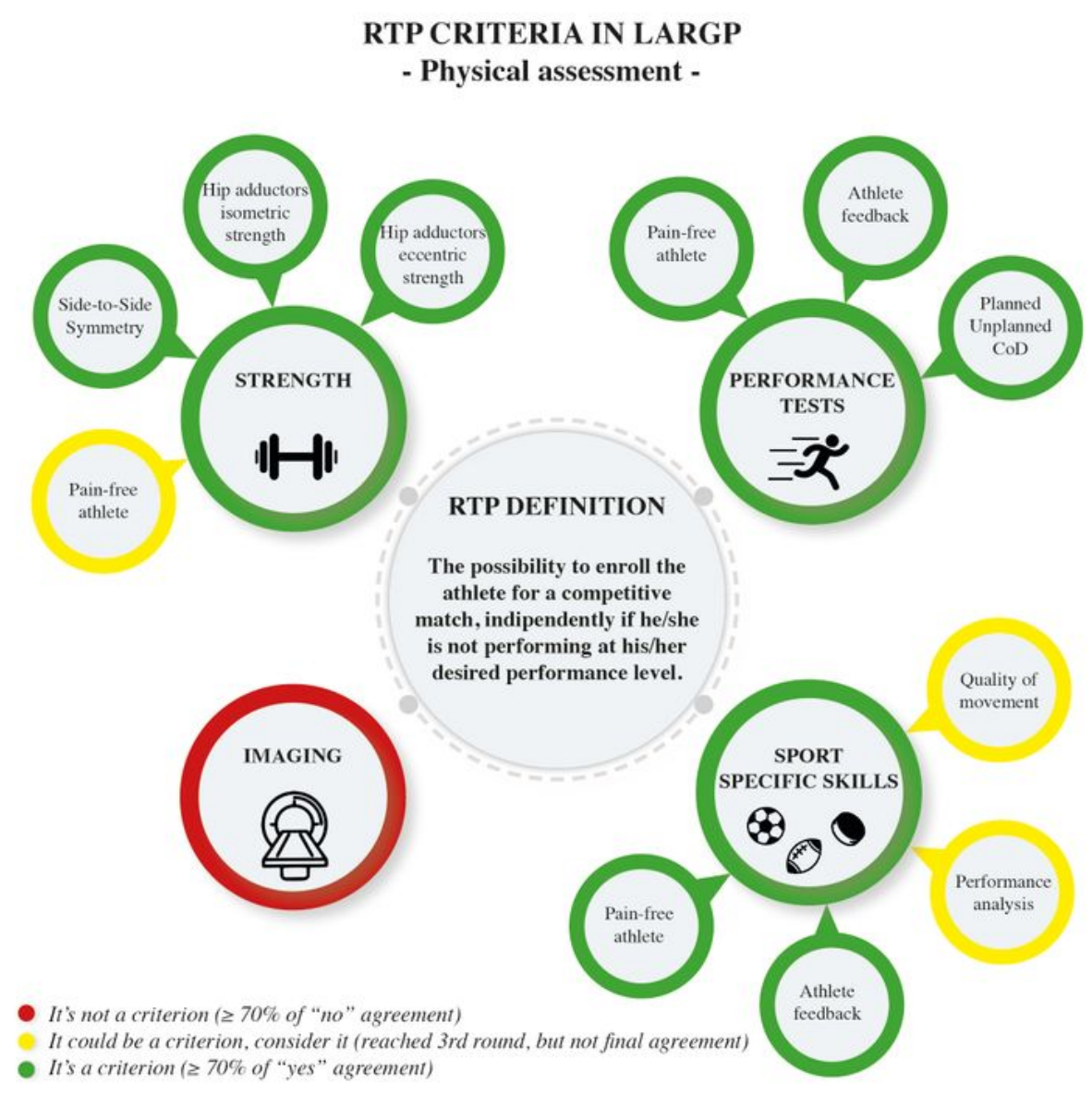

Figure 2

RTP criteria in Long-standing Adductor-Related Groin Pain (Physical Assessment)

\section{Supplementary Files}

This is a list of supplementary files associated with this preprint. Click to download. 
- 1SupplementaryTables.docx 